\title{
Morphological and Functional Changes in Schoolchildren with Bad Posture
}

\author{
${ }^{1}$ Elizabeta Leonid Popova Ramova, ${ }^{2}$ Leonid Zhivko Ramov
}

\begin{abstract}
Introduction: In the new millennium, the medical community still deals with the treatment of idiopathic scoliosis as a threedimensional (3D) curvature known in India before Hippocrates. However, we doctors that deal with deformities of the spine, stick to Reichalt's rule for treatment according to the size of the curvature and its progression. The aim of our study is to explain our own opinion for progression of bad posture in school children according to physical inactivity and use of video terminals (VT).

Materials and methods: We have made some researches about standards of school screening for bad posture and its impact on morphological and functional changes in them.
\end{abstract}

Results: Most of school children spend more than 2 hours in front of video terminals, they have increased body weight, and postural changes in sagittal plane.

Discussion: Some postural bad positions in age of intensive growth can became structural. In the era of fast technology development the future generation shall have functional changes on body like result of long standing in bad position.

Conclusion: The future studies for bad posture in school children should be aimed to find how much long sitting in front of VT can affect their health in the adult age.

Keywords: Bad posture, Functional changes, School screening.

How to cite this article: Ramova ELP, Ramov LZ. Morphological and Functional Changes in Schoolchildren with Bad Posture. Int J Recent Surg Med Sci 2016;2(2):114-115.

Sources of support: Nil

Conflict of interest: None

\section{INTRODUCTION}

In the new millennium, the medical community still deals with the treatment of idiopathic scoliosis as a three-dimensional (3D) curvature known in India before Hippocrates. ${ }^{1}$

Idiopathic scoliosis has an unpredictable natural history, which we cannot always successfully prevent,

${ }^{1}$ Professor, ${ }^{2}$ Student

${ }^{1}$ High Medical School, University St. Climent Ohridski, Bitola The Former Yugoslav Republic of Macedonia

${ }^{2}$ Faculty of Medical Sciences, Goce Delčev University of Štip Republic of Macedonia

Corresponding Author: Elizabeta Leonid Popova Ramova Professor, High Medical School, University St. Climent Ohridski Bitola The Former Yugoslav Republic of Macedonia, Phone: +0038975370864, e-mail: elizabeta.ramova@uklo.edu.mk despite our efforts to try and cure it. ${ }^{2}$ However, we doctors, who deal with deformities of the spine, stick to Reichelt's rule for treatment according to the size of the curvature and its progression. A curvature, with the size of $5^{\circ}$ to $25^{\circ}$, is treated with exercises, while a curvature from $25^{\circ}$ to $45^{\circ}$ is treated with exercises and a corset, and any curvature over $45^{\circ}$ can only progress with surgery. ${ }^{3}$

In my clinical experience from 1997 to 2009, I implemented exercises according to Schroth's method for correction of scoliosis curvature. The results were satisfactory with a $50 \%$ reduction in the curvature. Though it was not about big curvatures, it was about scoliosis up to $35^{\circ} .4$

While doing research, I noticed that many of the children who came for evaluation had structural scoliosis caused by improper posture. Literature suggests that, for scoliosis deformity, there are worldwide standards available to determine it (???). However, according to the school screening examination for early detection of deformities of the spine, there are no equal standards. ${ }^{5,6}$

School screening for deformities of the spine in some countries is omitted from health systems because of the cost and significance of the examination. The exclusion of evaluation of spinal deformities from the school screening examination has a $20 \%$ risk that children who have no significant deformity during a 6-monthperiod of intense bone growth get structural scoliosis, which cannot be prevented but only treated. ${ }^{7}$ In our health care system in Macedonia, systematic examinations of school children and high school students are done every 24 months, including a review of the spine deformity stating whether each child has or does not have kyphosis or scoliosis.

Average age of 9 to 14 years is the age of morphological growth, which is commonly involved in adaptation of wrong posture. For its prevention, a healthy diet, as well as physical activity, is needed at least 4 hours per week. ${ }^{8}$ In today's era of advanced technology, the use of video terminals from an earliest age has increased lower forced positions in the educational system and outside of it, as external factors increase the risk of a higher proportion of postural deformities. ${ }^{9}$

We still do not have information about how early and continued use of video terminals affects the physical health of the individual in later years and whether degenerative changes will be more expressed. During the preparation of my doctoral thesis, besides clinical 
examination for deformity of the spine with four clinical tests, we used a software program of Spine mouse for skin surface measurement of the deformity in sagittal plane. In addition to this, functional testing of the cardiopulmonary system was done by assessing blood pressure, cardiogram, and spirometry. ${ }^{10}$

It is known that structural scoliosis reduces respiratory capacity in children, and the reduced body weight is a risk factor. ${ }^{11}$

In our study, we found that individuals with postural deformity with reduced physical activity and lack of exercises had associated $60 \%$ deformity, increased body weight, as well as reduced vital capacity, while the extremely obese children have high blood pressure, even at the age of 10 years. $^{12}$

Earlier, postural and structural deformities as external factors were said to be because of very heavy schoolbags, carried symmetrically or asymmetrically. ${ }^{13}$ Today, if we analyze a schoolchild of age 10 to 14 years, who sits $>2$ hours/day on video display terminal, it is noticed that the child will have a significant change in posture, as marked cervical lordosis, shoulder protraction, pronounced thoracic kyphosis, and lower limbs in flexion. Kinesiology analysis gives an imbalance with a predominance of the flexors of the body, while with the correct posture the child returns to the evolution backward. Increased thoracic kyphosis causes reduced vital capacity and reduced physical ability. What happens to the blood vessels of the neck and their flow? What effect would they have on oxygenated blood supply to the brain? It is very common to have musculoskeletal shoulder pain in the neck area in early adulthood in workers of video terminals without structural bone changes. Will the increasing use of video terminals with the increased pressure on the spine causes faster aging of the bones? This should be the subject of research for new generations of schoolchildren. In our education system, there is one computer for each child in school, and it is intended for education. On average, it should not be used more than 1 hour a day, while according to physical education, it is accounted for 3 hours a week. The use of video terminals outside the education system is the responsibility of the parents, because the computer is used for playing games and entertainment.

In conclusion, it should be mentioned that in today's world, it does not matter which method is more successful in the treatment of spinal deformities and scoliosis. Rather, prevention is the cornerstone. Scoliosis worldwide is represented by 0.5 to $6 \%$. Literature states that postural deformities are increasing, affecting 45 to $60 \%$ of school population. Through national programs and measures, there should be an increase in health culture, as well as an increase in knowledge about the importance of corrective gymnastics and physical activity. This can act preemptively to prevent diseases of modern-day life, obesity, and poor posture, which in adulthood not only reduces the habit for fitness, but also is one of the main causes of diseases that burden the health system of each country.

\section{REFERENCES}

1. Heary RF, Madhavau K. The history of spinal deformity. Neurosurgery 2008 Sep;63(Suppl 3):5-15.

2. Weiss HR, Goodall D. The treatment of adolescent idiopathic scoliosis according to present evidence. A systematic review. Eur J Phys Rehabil Med 2008 Jun;44(2):177-193.

3. Reichelt, A. Orthopedie. Darmsttadt: Stein Kopff Verlag; 2000. p. 165-169.

4. Popova Ramova E, Poposka A, Lazovic M. School screening for bad posture with spine mouse device. MJMS 2010 Sep. doi: 10.3889/MJMS.1857-5773.2010.0117.

5. Grivas TB, Wade MN, Negrini S, O'Brien JP, Maruyama T, Hawes MC, Rigo M, Weiss HR, Kotwicki T, Vasiliadis ES, et al. SOSORT consensus paper: school screening for scoliosis: where we are today? Scoliosis 2007 Nov;2(1):17.

6. Grivas TB, Vasiliadis ES, O'Brien JP. How to improve the effectiveness of school screening for idiopathic scoliosis. Stud Health Technol Inform 2008;135:115-121.

7. Hawes CM, Brien JPO. The transformation of spinal curvature into spinal deformity: pathological processes and implication for treatment. Scoliosis 2006 Mar;1(1):3.

8. Loprinzi PD, Cardinal BJ, Loprinzi KL, Lee N. Benefits and environment determinants of physical activity in children and adolescents. Obes Facts 2012;5(4):597-610.

9. Popova Ramova E, Lazovic M. Prevention of spine deformities in adolescents due to inadequate posture. Med Rev 2010 Nov-Dec;63(11-12):855-859.

10. Popova Ramova E, Stoilova S. The effect of Schroth's exercises on bad posture correlation and vital capacity by school children age 10 years. Asian Acad Res J Soc Sci Humanities 2013 Dec;1(18).

11. Durmala J, Dobosiewiez K, Jendrzejek H, Pius W. Exercise efficiency of girls with idiopathic scoliosis based on the ventilator anaerobic threshold. Stud Health Technol Inform 2002 Feb;91:357-360.

12. Popova Ramova E, Poposka A, Ramov L. School screening for spine deformity with clinical test and spine mouse device. Jokull J 2013 Jul;63(7):97-105.

13. Korovessis P, Koureas G, Papazisis Z. Correlation between back pack weight and way of carrying, sagittal and frontal spine curvatures, athletic activity and dorsal and low back pain in school children and adolescents. J Spinal Discord Tech 2004 Feb;17(1):33-40. 